\title{
Changes in public support for alcohol policies in NSW, Australia, 2013-2019
}

\author{
Wendy L Watson ${ }^{a, c}$, Natalie Stapleton ${ }^{a}$, Penny Buykx ${ }^{b}$, Clare Hughes ${ }^{a}$ \\ and Anita Dessaixa
}

a Cancer Prevention and Advocacy Division, Cancer Council NSW, Sydney, Australia

b University of Newcastle, NSW, Australia

c Corresponding author: wendyw@nswcc.org.au

\section{Article history}

Publication date: 3 December 2021

Citation: Watson WL, Stapleton N, Buykx P, Hughes C, Dessaix A. Changes in public support for alcohol policies in NSW, Australia, 2013-2019. Public Health Res Pract. Online early publication; 2021. https:// doi.org/10.17061/phrp31452118

\section{Key points}

- Public support for policies to reduce harm associated with alcohol use changed little between 2013 and 2019, but decreased for policies about increasing price, applying a volumetric tax and reducing the number of alcohol outlets

- Survey participants who knew about the association of cancer risk with alcohol consumption were more supportive of alcohol policies

\section{Abstract}

Objectives: Alcohol contributes to significant health, social and economic burdens worldwide, but evidence-based policy options can reduce the harm associated with alcohol use. The aim of this paper is to understand factors influencing public support for various alcohol policies in New South Wales (NSW), Australia, and to determine any change over time.

Methods: An online survey of adults in NSW, in 2013 ( $n=2482), 2016$ ( $n=1585)$ and $2019(n=1601)$, assessed support for alcohol policies. Multivariable logistic regression models examined the change in support over time, adjusting for demographics, alcohol consumption, smoking status and knowledge of alcohol as a risk factor for cancer.

Results: Most participants (68-72\%) supported policies preventing underage internet users from exposure to alcohol advertising, and banning alcohol sponsorship of underage music and sporting events. Fiscal policies and restrictions on the number of alcohol outlets were the least supported policies (<40\% support). Compared with 2013, participants in 2016 and 2019 were less likely to support policies increasing price, applying a volumetric tax and reducing the number of alcohol outlets. In 2019, more than 55\% of respondents were aware that alcohol was a cancer risk factor, and knowledge of that relationship was associated with an increased likelihood of support for alcohol policies.

Conclusions: Support was greatest for alcohol harm-reduction policies that had less impact on an individual's drinking. Overall, support for alcohol policies in NSW is not increasing. Initiatives to raise awareness about the health consequences of alcohol use, together with effective alcohol policies, are needed to counter industry influence on decision makers and negative public discourse. 


\section{Introduction}

Australian drinking rates are among the highest in the world $^{1}$, and alcohol contributes to $4.5 \%$ of the Australian burden of disease. ${ }^{2}$ In 2013, 2.4\% of cancer deaths and $2.8 \%$ of cancer cases in Australia were attributed to alcohol. ${ }^{3}$ Alcohol use has both an economic cost, estimated as an annual productivity cost in Australia of \$1.1-6.8 billion ${ }^{4}$, and a social cost; one Australian study found that $70 \%$ of respondents were affected in some way by someone else's drinking, ranging from fear to physical harm. ${ }^{5}$

The World Health Organization deems policies related to alcohol price, availability and marketing as 'best buys' among policy options and interventions to address the substantial burden of alcohol on health, society and the economy. ${ }^{6}$ Governments play an integral role in applying evidence-based policies to reduce alcohol intake and minimise harm. Increasing public support for harm-reduction policies can increase the likelihood of governments implementing them. ${ }^{7}$

Internationally, public support for evidence-based alcohol policies varies. Support for alcohol policies across seven countries that participated in the International Alcohol Control Study ranged between $12 \%$ and $96 \%$. Support was consistently higher for policies addressing drink-driving or the minimum purchase age, and lower for pricing policies. ${ }^{8}$ International studies have also highlighted the fluidity of support for alcohol policies. 9,10 For example, in Ontario, Canada, during the 16 years to 2011, there was a decrease in support for policies such as reducing the number of alcohol outlets but a concurrent increase in support for policies such as alcohol taxation. ${ }^{9}$ In Australia, between 1993 and 2004, support decreased significantly for many alcohol policies. ${ }^{11}$ However, a later study assessing changes in support from 1995 to 2010, using questions from the same survey, found increased support since 2004 for many policy options related to alcohol availability and accessibility. ${ }^{12}$

Understanding population subgroups that are more supportive of alcohol policies, and factors that influence opinion, can inform advocacy approaches. Support for alcohol-related policies is generally higher in females, older people, lower-income populations and people who drink less. ${ }^{8,11}$ Knowledge of the harms associated with alcohol may also influence support for policies designed to minimise its negative consequences. Studies from Australia, Canada and the UK have observed an association between greater support for alcohol policies and awareness of alcohol as a risk factor for cancer. . $^{913-15}$

A multitude of factors influence policy decisions about alcohol, including lobbying by the alcohol industry ${ }^{16}$ and media criticism of government interventions. ${ }^{17}$ In February 2014, New South Wales (NSW) introduced restrictions aimed at reducing violence at night: no alcohol service after $3 \mathrm{am}$, no entry for new customers after $1.30 \mathrm{am}$ to licensed venues in high-risk areas of Sydney, and a state- wide ban on takeaway sales of alcohol after $10 \mathrm{pm} .{ }^{17}$ A coordinated campaign criticised the law ${ }^{17}$ until it was repealed in March 2021

This study follows public attitudes to policy options in NSW during the period 2013-2019 to help inform advocacy initiatives. The aims were to 1) assess changes in public support for alcohol policies in NSW from 2013 to 2019; and 2) examine if demographic, behavioural and knowledge factors are associated with greater support for alcohol policies.

\section{Methods}

The NSW Community Survey on Cancer Prevention investigates public attitudes and behaviours related to a range of cancer prevention topics. It was first conducted in $2013^{13}$, and then in 2016 and 2019.

NSW adults were recruited via a market research company to complete an online survey taking approximately 20 minutes. Panellists were recruited from online research panels (nonprobability access panel) via an email invitation and offered a small incentive to complete the survey. To be eligible, participants were required to be living in NSW, older than 18 years, and not currently receiving treatment for cancer. Neither the participant nor their family could be employed in advertising, or sales or manufacturing of alcohol or tobacco. The sample size was 3301 in 2013 (17.53\% response rate; 65\% completion rate), 3188 in 2016 (5\% response rate; $79 \%$ completion rate) and 3213 in 2019 (9.2\% response rate; $56 \%$ completion rate). Respondents were randomly allocated to answer questions on two of the following topics: nutrition and food, alcohol, sun protection, and tobacco. Across the three iterations, 5668 participants (of 9702) completed the alcoholspecific questions (2013: $n=2482$; 2016: $n=1585$; 2019: $n=1601)$.

Demographic information, including age, sex, location, household income and education, was collected. Postcode was used to derive an Index of Relative Socio-economic Disadvantage (IRSD), a general socioeconomic index based on the 2016 Australian Census. ${ }^{18}$ Participants were presented with standard drink images to guide responses on alcohol consumption. Alcohol consumption was measured using the Alcohol Use Disorders Test (AUDIT-C), a 3-item scale assessing frequency of alcohol consumption, usual consumption quantity and frequency of single-occasion heavy drinking (five or more drinks). ${ }^{19}$ AUDIT-C scores were categorised as no (score $=0$ ), low (1-2), medium (3-4) or high $(\geq 5)$; the higher the score, the greater the risk of alcohol-related harm. Participants selecting "don't know" were unable to have an AUDIT-C score calculated and were excluded from analysis.

Knowledge of alcohol as a risk factor for cancer was assessed using the question: "Which of the following do you think can result from drinking too much alcohol?" 
Cancer was listed, along with five other health conditions, and the response options were "yes", "no" and "don't know". The categories of "no" and "don't know" were combined into one category for analysis of whether knowledge influenced policy support.

To assess support for policy options, participants were asked the question: "To reduce problems associated with alcohol use, to what extent do you support or oppose ...?" and presented with the policy options listed in Table 2. Participants indicated opposition or support on a 5-point Likert scale from "strongly support" to "strongly oppose" or "don't know". The number of policy options presented varied across years $(2013=7 ; 2016=10 ; 2019=7)$ and evolved to focus on emerging policy opportunities (e.g. "banning alcohol sponsorship of youth-focused music events" was added in 2019).

Multivariable logistic regression examined the relationship between support for policy options over time for five policy questions common to all surveys, adjusting for the following variables: age, sex, education, IRSD, current smoking status, AUDIT-C score category and knowledge of alcohol as a risk factor for cancer. These variables were chosen based on previous studies that observed associations between these variables and levels of support for alcohol policies. ${ }^{11,13}$ Support for policy options were dichotomised into "support" ("support" and "strongly support") and "do not support" ("neither support nor oppose", "oppose" and "strongly oppose"). Because we were reporting on the support for policy options, "neither support nor oppose" was included in the "do not support" category. Those selecting "don't know" were reported as missing values and excluded (0-5\%). Categorical variables were year (2013, 2016, 2019), age (<40 years, 40-59 years, $\geq 60$ years), sex (male, female), IRSD (five quintiles), education ( $\leq$ year 10 , year 11 or 12, diploma/certificate, university), current smoker (yes, no), AUDIT-C score category (no, low, medium, high) and knowledge of alcohol as a risk factor for cancer (yes, no). All potential interactions of variables with year were undertaken and, if significant, retained in the final model. No models included residuals greater than 3 standard deviations.

All analyses were undertaken using IBM SPSS Statistics Subscription (Armonk, NY: IBM Corp; Version: Build 1.0.0.3581). Unweighted descriptive statistics were generated for demographic variables. All other results were weighted based on participants' age, sex, education and region to reflect the NSW population. The weighting included calibrating to account for differences between participants in online research panels and the rest of the population using benchmark questions from a national probability-based online panel.

Ethics clearance was provided by the Cancer Council NSW Ethics Committee (reference \#318).

\section{Results}

The characteristics of those who answered the alcohol questions are shown in Table 1. In 2019, 55.5\% of participants were aware that alcohol was a risk factor for cancer, an increase from $47.4 \%$ in 2013 and $49.8 \%$ in 2016.

Table 2 shows the proportion of participants who supported each alcohol policy initiative in each survey year. Policy options addressing exposure of young people to alcohol marketing received the highest levels of support; in 2019 , more than $70 \%$ of survey respondents supported laws protecting underage (younger than 18 years) internet users from alcohol advertising and banning alcohol sponsorship of youth-focused music events. Fiscal policies and reducing alcohol outlets generally received lower levels of public support (approximately $40 \%$ or less). Increasing the price of alcohol was consistently the least supported fiscal policy. In 2013 and 2016, support for three alcohol labelling initiatives ranged between $50.4 \%$ and $70.8 \%$, with generally higher levels of support in 2013 than in 2016 (these policies were not surveyed in 2019).

The logistic regression results are shown in Supplementary Table 1 (available from: 10.6084/ m9.figshare.16695580) and summarised here. Respondents were less likely to support policy options to increase price, apply a volumetric tax and reduce the number of outlets in 2016 and 2019 compared with 2013 (odds ratio [OR] range 0.74-0.82). Across all policy options, increasing age and knowledge of alcohol as a risk factor for cancer were positively associated with increased likelihood of support (OR range 1.02-2.44 and 1.39-1.77, respectively). Those who drank at higher risk levels were significantly less likely to support all five alcohol policies (OR range 0.1-0.51), as were those who smoked (OR range 0.55-0.68), except for the policy options to ban alcohol sponsorship of sporting events and reduce the number of outlets. The odds of supporting the following policies were higher for females than for males: laws protecting underage internet users from alcohol advertising, banning alcohol sponsorship of sport, and reducing the number of outlets. Higher levels of education were generally associated with increased likelihood of support for policies; this relationship was not significant for laws protecting underage internet users from exposure to alcohol advertising.

Logistic regression for the five consistent policy options showed an interaction between smoking status and survey year in three of the models, and between IRSD and survey year for the model analysing banning alcohol sponsorship of sport. For the models analysing increasing the price of alcohol and a tax on alcoholic drinks, among smokers there was an increase in support from 2013 to 2016 and no significant change in support from 2013 to 2019. For the model analysing banning alcohol sponsorship of sport, among smokers there was no significant change in support from 2013 to 2016 , 
Table 1. Sample characteristics by year (unweighted data)

\begin{tabular}{|c|c|c|c|}
\hline Characteristic & $\begin{array}{c}2013 \\
n=2482 \\
\%\end{array}$ & $\begin{array}{c}2016 \\
n=1585 \\
\%\end{array}$ & $\begin{array}{c}2019 \\
n=1601 \\
\%\end{array}$ \\
\hline \multicolumn{4}{|l|}{ Age group } \\
\hline$<40$ years & 36.0 & 34.3 & 38.1 \\
\hline 40-59 years & 39.1 & 40.1 & 32.0 \\
\hline$\geq 60$ years & 24.9 & 25.6 & 29.9 \\
\hline \multicolumn{4}{|l|}{ Sex ${ }^{a}$} \\
\hline Male & 49.2 & $44.9^{a}$ & 47.5 \\
\hline Female & 50.8 & $54.8^{a}$ & 52.5 \\
\hline \multicolumn{4}{|l|}{ Location } \\
\hline Sydney and suburbs & 63.4 & 63.0 & 68.4 \\
\hline Other NSW & 36.6 & 37.0 & 31.6 \\
\hline \multicolumn{4}{|l|}{ Education $^{b}$} \\
\hline$\leq$ Year 10 & 14.3 & 12.8 & 14.6 \\
\hline Year 11 or 12 & 16.5 & 14.4 & 20.0 \\
\hline Diploma/certificate & 36.7 & 38.0 & 32.0 \\
\hline $\begin{array}{l}\text { University } \\
\text { qualification }\end{array}$ & 32.5 & 34.2 & 32.5 \\
\hline
\end{tabular}

\section{$\mathrm{IRSD}^{\mathrm{c}}$}

\begin{tabular}{llll} 
Lowest quintile & 15.0 & 16.8 & 13.6 \\
Second quintile & 18.5 & 20.0 & 17.7 \\
Third quintile & 23.0 & 19.6 & 22.2 \\
Fourth quintile & 15.0 & 16.2 & 14.3 \\
Highest quintile & 28.4 & 27.1 & 32.0 \\
\hline
\end{tabular}

\begin{tabular}{llll}
\hline AUDIT-C category $^{d}$ & & & \\
No & 13.3 & 17.8 & 15.1 \\
Low & 25.3 & 26.5 & 25.0 \\
Medium & 24.8 & 23.9 & 24.9 \\
High & 35.8 & 29.7 & 32.7 \\
\hline
\end{tabular}

\section{Smoking status}

$\begin{array}{llll}\text { Current smoker (yes) } & 17.0 & 18.9 & 14.1\end{array}$

$\begin{array}{llll}\text { Current smoker (no) } & 83.0 & 81.1 & 85.9\end{array}$

\begin{tabular}{lccc}
\hline Knowledge of alcohol as a risk factor for cancer & \\
Yes & 47.4 & 49.8 & 55.5 \\
No & 28.7 & 28.1 & 24.0 \\
Don't know & 23.9 & 22.1 & 20.4 \\
\hline
\end{tabular}

NSW = New South Wales; AUDIT-C = Alcohol Use Disorders Test; IRSD = Index of Relative Socio-economic Disadvantage

a Missing values account for $0.3 \%$

b "I prefer not to say" not shown (2016: $n=10 ; 2019: n=14)$

c IRSD could not be established and is not shown for some respondents (2013: $n=2$; 2016: $n=5$; 2019: $n=4$ )

a AUDIT-C score not calculated for those selecting "don't know" for frequency of alcohol consumption and frequency of singleoccasion heavy drinking; these responses were excluded from analysis (2013: $n=20 ; 2016: n=33 ; 2019: n=37$ ). and a decrease in support from 2013 to 2019; for this model, there was also an apparent greater increase in support from 2013 to 2016 and from 2013 to 2019 for IRSD quintiles 2 and 5 (highest) compared with quintiles 3 and 4.

\section{Discussion}

There was limited change in the proportion of people supporting policies designed to reduce harm from alcohol across the three surveys between 2013 and 2019. Some of the results can be compared to those from the NSW results in Australia's 2019 National Drug Strategy Household Survey where the same questions were asked but to those aged 14 years and older. ${ }^{20}$ The results of our 2019 community study are within 3 percentage points of the NSW results in the Household Survey for increasing the price $(30.3 \%$ vs $28.0 \%)$, and banning sponsorship of sport (54.7\% vs $55.2 \%$ ) and within 5 percentage points for decreasing the number of outlets (35.1\% vs $30.3 \%$ ) and increasing the tax on alcohol to pay for health, education, and the cost of treating alcohol related problems (39.7\% vs $44.0 \%) .{ }^{20}$ Consistent with previous findings, policies with no direct impact on an individual's drinking had the greatest support, whereas more restrictive policies that might affect an individual's own behaviours, such as price and availability, were least supported. ${ }^{21}$ Similar to a recent survey ${ }^{22}$, increasing the price of alcohol was the least supported price-based policy. Increasing the tax on alcohol to pay for health and treatment costs received more support than simply increasing the price of alcohol. This is important for policy makers to know when framing policies, and is consistent with other studies showing more support for taxation when those taxes are directed into harm-reduction programs or into offsetting the cost of alcohol-related harm. ${ }^{22,23}$

Analysis of changes over time showed that the likelihood of supporting some policy options was lower in 2016 and 2019 than in 2013. Previous Australian studies initially observed a general drop in support for alcohol policies from 1995 to 2004, and an increase in support from 2004 to $2010 .{ }^{11,12}$ These studies were unable to identify the underlying reasons driving changes in support, but their findings demonstrate that policy support is not static and can change in either a positive or negative direction.

Between the first and last time points of this current study, state-specific laws aimed at reducing alcoholrelated violence at night were introduced following two deaths from alcohol-related violence, the most recent a month before the 2013 survey. ${ }^{17,24}$ These laws, introduced in February 2014, applied restrictions to venues in high-risk areas of Sydney and a statewide ban on takeaway sales of alcohol after $10 \mathrm{pm}$. There was a highly organised and persistent public campaign (described elsewhere ${ }^{17}$ ) against these policies, from the time the law was implemented, throughout a review 
Table 2. Support for alcohol policies by year (weighted)a

\begin{tabular}{|c|c|c|c|}
\hline Policy option ${ }^{a}$ & $\begin{array}{l}2013 \\
\% \text { support }\end{array}$ & $\begin{array}{l}2016 \\
\text { \% support }\end{array}$ & $\begin{array}{l}2019 \\
\% \text { support }\end{array}$ \\
\hline \multicolumn{4}{|l|}{ Pricing policies } \\
\hline Increasing the price of alcoholb & 28.2 & 29.7 & 30.3 \\
\hline $\begin{array}{l}\text { Increasing the tax on alcohol products to pay for health, education } \\
\text { and the cost of treating alcohol-related problems }\end{array}$ & NA & 40.3 & 39.7 \\
\hline $\begin{array}{l}\text { Taxing alcoholic drinks based on the percentage of alcohol they } \\
\text { contain }^{b}\end{array}$ & 40.4 & 38.6 & 40.2 \\
\hline
\end{tabular}

\title{
Marketing policies
}

Laws aiming to restrict underage internet users being exposed to alcohol advertising ${ }^{b}$

Limiting alcohol advertising on TV until after 9:30 pm

68.2

69.6

71.9

Banning alcohol sponsorship of sporting events ${ }^{b}$

NA

68.9

NA

Banning alcohol sponsorship of youth-focused music events

46.5

49.6

54.7

Labelling policies

Specific health warnings on alcohol containers (e.g. like those on tobacco packaging)

Increasing the size of standard drink labels on alcohol containers

NA

NA

70.6

Requiring information on national drinking guidelines on all alcohol containers

$\begin{array}{lll}70.8 & 59.9 & \text { NA } \\ 69.2 & 50.4 & \text { NA } \\ 64.7 & 61.6 & \text { NA }\end{array}$

\section{Availability}

Reducing the number of outlets that sell alcohol ${ }^{b}$

37.1

34.4

35.1

\begin{abstract}
NA = not applicable
a Total respondents: $N=5668$ (2013: $n=2482 ; 2016: n=1585 ; 2019: n=1601)$. Data missing from each of the questions (in total, and per survey year): increasing price, $N=149$ (2013: $n=21 ; 2016: n=66 ; 2019: n=62)$; increasing tax to pay for other services, $N=137$ (2016: $n=71 ; 2019: n=66)$; taxing drinks on basis of percentage alcohol, $N=198$ (2013: $n=35 ; 2016: n=82 ; 2019: n=81)$; laws restricting underage internet users, $N=163$ (2013: $n=27 ; 2016: n=73 ; 2019: n=63)$; limiting advertising until after 9.30 pm, $N=56$ (2016: $n=56$ ); banning alcohol sponsorship of sport, $N=128$ (2013: $n=9 ; 2016: n=62 ; 2019: n=57$ ); banning alcohol sponsorship of youth-focused music festivals, $N=58$ (2019: $n=58$ ); health warning label, $N=78$ (2013: $n=10 ; 2016: n=68)$; increasing size of standard drink labels, $N=117$ (2013: $n=21 ; 2016: n=96)$; guidelines on alcohol products, $N=105$ (2013: $n=34 ; 2016: n=71)$; reducing outlets, $N=163$ (2013: $n=23$; 2016: $n=75 ; 2019: n=65)$.

b Policy question included in statistical analysis to examine the relationship between support for policy options over time Note: "Don't know" was included as missing values.
\end{abstract}

announced in February 2016, and into the survey period in 2019. Support for late trading policies fell substantially between 2013 and 2016, particularly in NSW. ${ }^{17}$ In that period, Livingston et al. also found a decrease in support for evidence-based policy in NSW compared with many other Australian states. ${ }^{17}$ Our results, showing a decrease in support over time for policies relating to the availability of alcohol, reflect that observation. The restrictions on venues and the public discourse about government intervention that surrounded that legislative change in NSW may have contributed to this decrease. Livingston et al. found that attitudes changed even among those not affected by the policy, and speculated that this may have been because of the influence of public discourse. ${ }^{17}$ Further research is needed to establish whether and how public discourse affects policy support among those not directly affected by a policy, because this could have implications for future advocacy and lessons for policy makers.

As in previous studies, those who were more likely to support alcohol harm-reduction policies were female, were older, had a university education, were lower-risk drinkers, were nonsmokers and were aware that alcohol increases cancer risk. ${ }^{11,21,25}$ Diepeveen et al. suggested that females often have healthier behaviours than males; thus many of the policies may be less intrusive for them. ${ }^{21}$ Furthermore, older adults may be more trusting of government or have higher levels of knowledge about the harms of products such as alcohol, which influence their higher levels of support. ${ }^{21}$

Knowledge of alcohol as a risk factor for cancer has been associated with increased likelihood of supporting alcohol harm-reduction policies. ${ }^{13-15}$ Weerasinghe et al. found that increased knowledge of alcohol as a cancer 
risk factor, achieved through a labelling intervention, almost doubled the likelihood that an individual would support pricing policies. ${ }^{14}$ Educating the public on the risk of cancer linked to alcohol consumption is an opportunity to improve public support for alcohol policies. ${ }^{13}$

Our 2019 survey found that $55.5 \%$ of respondents were aware that alcohol is a cancer risk factor, an increase from previous surveys. Possible contributors to this increase are consumer education campaigns or media coverage during this time. Cancer Council NSW delivered a public education campaign, ' 1 in 3 Cancers', from September 2016 to December 2016 and from May 2017 to July 2017, highlighting that one in three cancers could be prevented with behavioural changes, including drinking less alcohol. ${ }^{26}$ Education campaigns focusing on the increased risk of cancer associated with alcohol consumption have contributed to an increased knowledge of this link. ${ }^{27}$ Policy support is complex and multidimensional ${ }^{25}$, and both individuals' knowledge of the harms and their perception of the effectiveness of policy options can influence public support for alcohol policies. ${ }^{28,29}$ Also, individuals' experiences of alcoholrelated harm from others have been linked to greater support for policy measures. ${ }^{30}$ Developing effective framing of policies, providing education to the public, and building and strengthening relationships with stakeholders, particularly in the community, can all be used to improve public support. ${ }^{7,21}$ Although our study has shown an increase in knowledge, we have not seen a corresponding increase in support. This could be attributable to many factors, including NSW-specific dialogue about restrictions on alcohol availability and ongoing lobbying by the industry. The latter may be another area where public support can be used to advocate for better control over industry-government relationships and lobbying. ${ }^{16}$

\section{Limitations}

The surveys were conducted in a single state in Australia, limiting the applicability of the findings to other states, territories and countries. Local challenges could influence the public's support, or lack thereof, for alcohol policies. However, the findings are consistent with other studies. The research was conducted online using an online research panel; this could potentially introduce bias into results because participants who self-select to participate in market research may not represent people who do not access the internet or do not choose to join a panel. The weighting included accounting for nonresponse bias and calibration with a probability-based online panel to reduce the risk of bias associated with this methodology. It is not known if the sampling strategy affected the comparability of time points, because different research panels were used at each time point, but the methodology for obtaining a NSW population sample was consistent. The participation rates differed between study time points. Each survey was conducted by a different market research company, and the difference in participation rates may be a measure of differences in the membership of each online panel or the percentage of active panel members. The authors cannot speculate if participation rates influenced the results, but quota sampling was put in place to mitigate this. The current policy questions are unidimensional and do not uncover reasons for support or lack of support for these policies. Future research could focus on identifying reasons why some policies are not supported.

\section{Conclusion}

This study shows limited changes in public support for alcohol harm-reduction policies in NSW between 2013 and 2019. Some population subgroups remain more supportive of alcohol policies, including those with increased knowledge of harms associated with alcohol consumption, specifically cancer risk. Raising awareness of the health consequences of alcohol intake and the effectiveness of evidence-based alcohol policies, alongside advocating for strategies to control lobbying by those with commercial interests, are ways civil society can help increase the likelihood of these policies being implemented.

\section{Acknowledgements}

We wish to thank David Goldsbury and Peter Sarich, Cancer Council NSW, for advice and support for data analysis and interpretation.

$\mathrm{AD}$ and $\mathrm{CH}$ received a grant from the NIB Foundation for work on an alcohol and cancer social marketing campaign.

\section{Peer review and provenance}

Externally peer reviewed, not commissioned.

\section{Competing interests}

None declared.

\section{Author contributions}

WW and NS were responsible for design, drafting and data analysis. PB was responsible for data interpretation and manuscript review. $\mathrm{CH}$ was responsible for design and manuscript review. AD was responsible for overseeing data acquisition and manuscript review. All authors edited the manuscript. 


\section{References}

1. World Health Organization. Global status report on alcohol and health 2018. Geneva: WHO; 2018 [cited 2021 Sep 8]. Available from: www.who.int/publications/i/ item/9789241565639

2. Australian Institute of Health and Welfare. Australian burden of disease study: impact and causes of illness and death in Australia 2015. Summary report. Canberra: AlHW; 2019 [cited 2021 Sep 8]. Available from: www. aihw.gov.au/getmedia/08eb5dd0-a7c0-429a-b35fc8275e7a1dbf/aihw-bod-21.pdf.aspx?inline=true

3. Wilson LF, Antonsson A, Green AC, Jordan SJ, Kendall BJ, Nagle CM, et al. How many cancer cases and deaths are potentially preventable? Estimates for Australia in 2013. Int J Cancer. 2018;142(4):691-701.

4. Crosland P, Ananthapavan J, Davison J, Lambert M, Carter R. The economic cost of preventable disease in Australia: a systematic review of estimates and methods. Aust N Z J Public Health. 2019;43(5):484-95.

5. Laslett AM, Room R, Ferris J, Wilkinson C, Livingston M, Mugavin J. Surveying the range and magnitude of alcohol's harm to others in Australia. Addiction. 2011;106(9):1603-11.

6. World Health Organization. Best buys and other recommended interventions for the prevention and control of noncommunicable diseases. Updated Appendix 3 of the global action plan for the prevention and control of NCDs 2013-2020. Geneva: WHO; 2017 [cited 2021 Sep 8]. Available from: www.who.int/ncds/ management/WHO_Appendix_BestBuys.pdf

7. Huang TT, Cawley JH, Ashe M, Costa SA, Frerichs LM, Zwicker L, et al. Mobilisation of public support for policy actions to prevent obesity. Lancet. 2015;285(9985):242231.

8. Parry CDH, Londani M, Enkhtuya P, Huckle T, Piazza M, Gray-Phillip G, et al. Support for alcohol policies among drinkers in Mongolia, New Zealand, Peru, South Africa, St Kitts and Nevis, Thailand and Vietnam: data from the International Alcohol Control Study. Drug Alcohol Rev. 2018;37 Suppl 2:S72-85.

9. Ialomiteanu AR, Giesbrecht N, Adlaf EM, Wettlaufer A. Trends in public opinion on alcohol issues during a period of increasing access to alcohol: Ontario, Canada, 1996-2011. Drug Alcohol Rev. 2014;33(3):249-58.

10. Rossow I, Storvoll EE. Long-term trends in alcohol policy attitudes in Norway. Drug Alcohol Rev. 2014;33(3):220-6.

11. Wilkinson C, Room R, Livingston M. Mapping Australian public opinion on alcohol policies in the new millennium. Drug Alcohol Rev. 2009;28(3):263-74.

12. Callinan S, Room R, Livingston M. Changes in Australian attitudes to alcohol policy: 1995-2010. Drug Alcohol Rev. 2014;33(3):227-34.
13. Buykx P, Gilligan C, Ward B, Kippen R, Chapman K. Public support for alcohol policies associated with knowledge of cancer risk. Int J Drug Policy. 2015;26(4):371-9.

14. Weerasinghe A, Schoueri-Mychasiw N, Vallance K, Stockwell T, Hammond D, McGavock J, et al. Improving knowledge that alcohol can cause cancer is associated with consumer support for alcohol policies: findings from a real-world alcohol labelling study. Int J Environ Res Public Health. 2020;17(2).

15. Bates S, Holmes J, Gavens L, de Matos EG, Li J, Ward B, et al. Awareness of alcohol as a risk factor for cancer is associated with public support for alcohol policies. BMC Public Health. 2018;18(1):688.

16. Miller P, Martino F, Robertson N, Stafford J, Daube M. Public opinion of alcohol industry corporate political activities. Aust N Z J of Public Health. 2021;45(3):283-9.

17. Livingston $\mathrm{M}$, Callinan $\mathrm{S}$, Wilkinson $\mathrm{C}$. The impact of high profile restrictions on support for alcohol control policies. Drug Alcohol Rev. 2019;38(4):399-405.

18. Australian Bureau of Statistics. Census of population and housing: socio-economic indexes for areas (SEIFA), Australia, 2016. Canberra: ABS; 2018 [updated 2018 Mar 27] [cited 2020 Nov 17]. Available from: www.abs.gov.au/ausstats/abs@.nsf/Lookup/ by\%20Subject/2033.0.55.001 2016 Main\%20 Features IRSD 19

19. Bush K, Kivlahan DR, McDonell MB, Finn SD, Bradley KA. The AUDIT alcohol consumption questions (AUDIT-C): an effective brief screening test for problem drinking. Ambulatory Care Quality Improvement Project (ACQUIP). Alcohol use disorders identification test. Arch Intern Med. 1998;158(16):1789-95.

20. Australian Institute of Health and Welfare. National Drug Strategy household survey 2019. Canberra: AlHW; 2020 [cited 2021 Sep 8]. Available from: www.aihw.gov.au/ getmedia/77dbea6e-f071-495c-b71e-3a632237269d/ aihw-phe-270.pdf.aspx?inline=true .

21. Diepeveen S, Ling T, Suhrcke M, Roland M, Marteau TM. Public acceptability of government intervention to change health-related behaviours: a systematic review and narrative synthesis. BMC Public Health. 2013;13:756.

22. Cook M, Livingston M, Vally H, Callinan S. Australians' support for alcohol price-based policies. Int J Drug Policy. 2020;85:102924.

23. Wagenaar AC, Harwood EM, Toomey TL, Denk CE, Zander KM. Public opinion on alcohol policies in the United States: results from a national survey. J Public Health Policy. 2000;21(3):303-27.

24. Kypri K. Science, politics, and the play of chance in recent Australian drinking law changes. Drug Alcohol Rev. 2016;35(6):657-60. 
25. Li J, Lovatt M, Eadie D, Dobbie F, Meier P, Holmes J, et al. Public attitudes towards alcohol control policies in Scotland and England: results from a mixed-methods study. Soc Sci Med. 2017;177:177-89.

26. Wellard-Cole L, Watson WL, Walsberger S, Hughes C, Chapman K. Overcoming knowledge gaps on the links between weight, diet, physical activity and cancer risks: lessons from the '1 in 3 Cancers' prevention campaign. Victoria, BC, Canada: Abstract Book International Society of Behavioral Nutrition and Physical Activity Annual Meeting; 2017. ISBN: 978-0-692-88370-9

27. Dixon HG, Pratt IS, Scully ML, Miller JR, Patterson C, Hood R, Slevin TJ. Using a mass media campaign to raise women's awareness of the link between alcohol and cancer: cross-sectional pre-intervention and post-intervention evaluation surveys. BMJ Open. 2015;5(3):e006511.
28. Storvoll EE, Rossow I, Rise J. Changes in attitudes towards restrictive alcohol policy measures: the mediating role of changes in beliefs. J Subst Use. 2014;19(1-2):38-43.

29. Storvoll EE, Moan IS, Rise J. Predicting attitudes toward a restrictive alcohol policy: Using a model of distal and proximal predictors. Psychol Addict Behav. 2015;29(2):492-9.

30. Greenfield TK, Karriker-Jaffe KJ, Giesbrecht N, Kerr WC, Ye Y, Bond J. Second-hand drinking may increase support for alcohol policies: new results from the 2010 National Alcohol Survey. Drug Alcohol Rev. 2014;33(3):259-67.

\section{Copyright: (c) (i) (2)}

(C) 2021 Watson et al. This article is licensed under the Creative Commons Attribution-NonCommercial-ShareAlike 4.0 International Licence, which allows others to redistribute, adapt and share this work non-commercially provided they attribute the work and any adapted version of it is distributed under the same Creative Commons licence terms. See: www.creativecommons.org/licenses/by-nc-sa/4.0/ 